\title{
Dissipation Dynamics and Residue of Four Herbicides in Paddy Fields Using HPLC-MS/MS and GC-MS
}

\author{
Qian Yu ${ }^{1,2,+}$, Ping Zhang ${ }^{1,2, *,+}$, Yuhan $\mathrm{He}^{1,2}$, Zhifeng $\mathrm{Xu}^{1,2}$, Xiulong $\mathrm{He}^{1,2}$, Yuan $\mathrm{Hu}^{1,2}$, \\ Hongjun Zhang ${ }^{3}$ and Lin $\mathrm{He}^{1,2, *}$ \\ 1 Key Laboratory of Entomology and Pest Control Engineering, College of Plant Protection, \\ Southwest University, Chongqing 400715, China; qianyu_swu@163.com (Q.Y.); ping17028@163.com (Y.H.); \\ xzf2018@swu.edu.cn (Z.X.); zpcauz@163.com (X.H.); pingz028@163.com (Y.H.) \\ 2 Academy of Agricultural Sciences, Southwest University, Chongqing 400715, China \\ 3 Institute for the Control of Agrochemicals, Ministry of Agriculture, Beijing 100125, China; \\ zhanghongjun@agri.gov.cn \\ * Correspondence: pingz@swu.edu.cn (P.Z.); helinok@vip.tom.com (L.H.); Tel.: +86-23-68251541; \\ Fax: +86-23-68251514 \\ + These authors contributed equally to this paper.
}

Received: 30 November 2018; Accepted: 11 January 2019; Published: 15 January 2019

\begin{abstract}
The dissipation dynamics and residue of pyrazosulfuron-ethyl, bensulfuron-methyl, acetochlor, and butachlor in paddy fields at Good Agricultural Practices (GAP) condition were carefully investigated in this study. The four herbicides' residues were determined based on a quick, easy, cheap, rugged, safe (QuEChERS) method coupled with HPLC-MS/MS and GC-MS. The limit of detection (LOD) for pyrazosulfuron-ethyl, bensulfuron-methyl, acetochlor, and butachlor in all matrices ranged from 0.04-1.0 ng. The limit of quantification (LOQ) of the four herbicides ranged from $0.01-0.1 \mathrm{mg} / \mathrm{kg}$. Moreover, the average recoveries of the four herbicides ranged from $78.9-108 \%$ with relative standard deviations (RSDs) less than $15 \%$ at three different fortified levels for different matrices. The dissipation results indicated that the average half-lives $\left(t_{1 / 2}\right)$ of the four herbicides in soil were in the range of 3.5-17.8 days, and more than $95 \%$ of the four herbicides dissipated within 5 days in water. Furthermore, the final residues of the four herbicides were all below the LOQ at harvest time. Such results highlight the dissipation dynamics and residue of the four herbicides in a rice cropping system and contribute to risk assessment as well as scientific guidance on the proper and safe application of herbicides in paddy fields.
\end{abstract}

Keywords: herbicide; dissipation; residue; rice; HPLC-MS/MS; GC-MS

\section{Introduction}

Rice (Oryza sativa L.) is the most important grain and widely cultivated in China [1-4]. Thus, the quality and safety of rice are highly related to human health and national strategies. Due to the long growth period of rice, weed problems appear frequently in paddy fields, which compete with rice for space, light, water, and nutrients, leading to a loss of about half of rice production [5,6]. With higher yield and quality requirements for rice, herbicides have been extensively used in paddy fields for weed control. Furthermore, the sales of herbicides have become the largest in the pesticide industry, and the wide use of herbicides in agriculture inevitably leads to higher residues in the environment [7]. Studies indicate that herbicide residues could migrate into soil and water after application, which poses a great threat to the quality and safety of rice, as well as human health $[8,9]$. 
Pyrazosulfuron-ethyl ethyl 5-[(4,6-dimethoxypyrimidin-2-yl)carbamoylsulfamoyl]-1 -methylpyrazole-4-carboxylate, and bensulfuron-methyl methyl 2-[(4,6-dimethoxypyrimidin-2-yl) carbamoylsulfamoylmethyl]benzoate are two commonly used rice herbicides belonging to the sulfonylurea group, which are generally used to control sedges and broadleaf weeds (Figure 1) $[10,11]$. The action mechanism of sulfonylurea herbicides is to inhibit acetolactate synthase (ALS) activity and block the biosynthesis of branched-chain amino acids of weeds [12]. Acetochlor 2-chloro-N-(ethoxymethyl)-N-(2-ethyl-6-methylphenyl)acetamide and butachlor $\mathrm{N}$-(butoxymethyl)-2-chloro-N-(2,6-diethylphenyl)acetamide are two chloroacetanilide herbicides generally used in rice fields for pre-emergent control of annual grasses and broadleaf weeds $[13,14]$. The four herbicides inhibit the growth of young shoots and roots, stimulate root-like deformities, and lead to the death of weeds after application in rice cropping systems [15-18]. Although the half lethal doses $\left(\mathrm{LD}_{50}\right)$ of four herbicides in rats are all over $5000 \mathrm{mg} / \mathrm{kg}$ according to the Pesticide Manual [19], the four herbicides are extensively used in paddy fields in consideration of good selectivity, high efficiency, and low toxicity. Previous studies primarily concentrated on herbicidal activity and residue levels of four herbicides in rice cropping systems $[10,20,21]$. The results indicated that pyrazosulfuron-ethyl, bensulfuron-methyl, acetochlor and butachlor were safe and the residues in rice were lower than the maximum residue limit (MRL) at the recommended dosage $[19,20]$. However, weed resistance to these four herbicides increased gradually due to widespread use in paddy fields, which inevitably increased the dosage of these four paddy herbicides [22-25]. Such phenomenon constitutes a serious threat to cropping ecosystem assessment and herbicide residues in rice.<smiles>COc1cc(OC)nc(NC(=O)NS(=O)(=O)c2c(OC)cnn2C)n1</smiles>

Pyrazosulfuron-ethyl<smiles>COc1cc(OC)nc(NC(=O)NS(=O)(=O)Cc2ccccc2C(C)=O)n1</smiles>

Bensulfuron-methyl

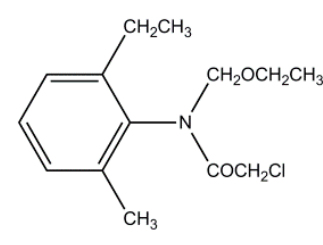

Acetochlor

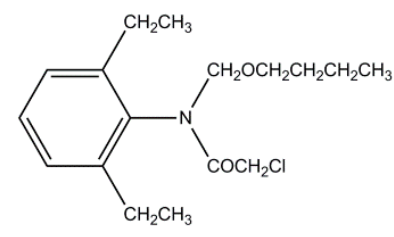

Butachlor

Figure 1. Chemical structures of pyrazosulfuron-ethyl, bensulfuron-methyl, acetochlor, and butachlor.

Considering the complexity of matrices in paddy fields, a sensitive, rapid, and reliable sample preparation method is necessary, which should facilitate extraction, enhance enrichment of the target compound, and reduce interferences as much as possible. Solid-phase extraction, supercritical-fluid extraction, liquid-liquid extraction and QuEChERS are generally adopted in paddy sample preparation, and QuEChERS is the most frequently used method [26]. Analytical methods for pyrazosulfuron-ethyl and bensulfuron-methyl have been mainly focused on high performance liquid chromatography (HPLC) [27], capillary electrophoresis (CE) [28], gas chromatography-tandem mass spectrometry (GC-MS) [29], immunoassay [30], and liquid chromatography-tandem mass spectrometry (LC-MS) [31]. Acetochlor and butachlor analysis have been primarily performed on GC [32], HPLC [21], and GC-MS [33]. HPLC-MS/MS and GC-MS have higher sensitivity and precision and lower detection 
limits than traditional methods at trace levels in various matrices [34,35]. In addition, the combination of QuEChERS and mass spectrometry has been considered as the most sensitive, rapid, and reliable method for pesticide residue analysis in different matrices.

In this study, a simple and reliable QuEChERS method coupled with HPLC-MS/MS and GC-MS methods was established to determine pyrazosulfuron-ethyl, bensulfuron-methyl, acetochlor, and butachlor residues in rice cropping systems. The dissipation dynamics of the four herbicides in water and soil, as well as the final residues in rice hull and husked rice, were carefully investigated under Good Agricultural Practices (GAP) use. Such results highlight the dissipation dynamics and residue of the four herbicides in rice cropping systems and contribute to risk assessment of herbicide residues in rice, as well as providing scientific guidance on the proper and safe application of rice herbicides in paddy fields.

\section{Materials and Methods}

\subsection{Chemicals and Equipment}

Pyrazosulfuron-ethyl (purity $=95 \%$ ), bensulfuron-methyl (purity $=97 \%$ ), acetochlor (purity $=92 \%)$, and butachlor (purity $=92.5 \%$ ) were obtained from the Institute for Control of Agrochemicals (Beijing, China). Pyrazosulfuron-ethyl WP (10\%), bensulfuron-methyl WP $(10 \%)$, acetochlor WP $(10 \%)$, and butachlor EC $(900 \mathrm{~g} / \mathrm{L})$ were purchased from commercial sources. Acetonitrile, methanol, and formic acid were HPLC grade and purchased from Thermo Fisher Scientific (Waltham, MA, USA). Ethyl acetate, acetone, sodium chloride, and anhydrous magnesium sulfate were analytical grade and bought from J\&K Scientific Co., Ltd. (Beijing, China). Graphitized carbon black (GCB) and primary secondary amine (PSA) were purchased from Agela Technologies (Tianjing, China). Ultra-pure water was generated using a Milli-Q purification system from Millipore (USA). Pyrazosulfuron-ethyl, bensulfuron-methyl, acetochlor, and butachlor stock standard solutions were prepared with corresponding organic solvent and stored at $-20^{\circ} \mathrm{C}$.

Pyrazosulfuron-ethyl and bensulfuron-methyl were analyzed on an Agilent 6410 high performance liquid chromatography-tandem triple quadrupole mass spectrometry equipped with electrospray ionization source (Agilent Technologies, Santa Clara, CA, USA). An Agilent 7890-5977B gas chromatography-tandem mass spectrometry (Agilent Technologies, USA) was used to determine acetochlor and butachlor. A Sigma 3K15 microcentrifuge (St. Louis, MO, USA), Xiangyi L550 centrifuge (Hunan, China), ME204 analytical balance (Sartorius, Germany), IKA T18 grinder (IKA, Germany), and ZWFR-200 shaker (Zhicheng, China) were adopted in sample preparation.

\subsection{Field Experiment Design}

Field experiments including the degradation dynamics and final residues in supervised field trials were conducted in Chongqing municipality in 2017 (Table 1). All the experiments were designed based on the "Guidelines on pesticide residue trials (NY/T 788-2004)" published by the Institute for the Control of Agrochemicals, Ministry of Agriculture and Rural Affairs of the People's Republic of China [36]. The area of the field experiment plot was $30 \mathrm{~m}^{2}$ and each treatment had three replicated plots. Furthermore, a buffer area was designed to isolate the experiment plots.

The degradation dynamics experiments were conducted with two dosage levels, pyrazosulfuron-ethyl (22.5 $\mathrm{g}$ a.i.ha ${ }^{-1}$, the recommended dosage and $45 \mathrm{~g}$ a.i.ha ${ }^{-1}$, double of the recommended dosage), bensulfuron-methyl $\left(26.2 \mathrm{~g}\right.$ a.i.ha ${ }^{-1}$, the recommended dosage and $52.4 \mathrm{~g}$ a.i.ha ${ }^{-1}$, double of the recommended dosage), acetochlor (52.5 $\mathrm{g}$ a.i.ha ${ }^{-1}$, the recommended dosage and $105 \mathrm{~g}$ a.i.ha ${ }^{-1}$, double of the recommended dosage) and butachlor (112.4 $\mathrm{g}$ a.i.ha ${ }^{-1}$, the recommended dosage and $224.8 \mathrm{~g}_{\text {a.i.ha }}{ }^{-1}$, double of the recommended dosage), respectively. All the four herbicides were sprayed one time after rice transplanting. Representative $2 \mathrm{~kg}$ paddy soil and $500 \mathrm{~mL}$ water samples were collected randomly in each plot at 0 ( $2 \mathrm{~h}$ post-treatment), 5, 10, 20, 30, 40, 80 days and pre-harvest interval (PHI) of 7 days after herbicides application. The representative 
$2 \mathrm{~kg}$ rice samples were randomly collected at pre-harvest interval (PHI) of 7 days. All the collected paddy soil, water, and rice samples were stored at $-20^{\circ} \mathrm{C}$, respectively.

Table 1. The location of experimental plots.

\begin{tabular}{ccc}
\hline No. & Experimental Plots & Location \\
\hline 1 & BB-01 & $106.368,29.747689$ \\
2 & BB-02 & $106.389278,29.881666$ \\
3 & BS-01 & $106.11499,29.534675$ \\
4 & BS-02 & $106.159433,29.613598$ \\
5 & HC-01 & $106.397122,30.125637$ \\
6 & HC-02 & $106.181094,30.185661$ \\
7 & JJ-01 & $106.273947,29.073062$ \\
8 & JJ-02 & $106.276326,29.14402$ \\
9 & TN-01 & $105.809623,30.20763$ \\
10 & TN-02 & $105.836951,30.233446$ \\
\hline
\end{tabular}

\subsection{Analytical Procedure}

\subsubsection{Sample Preparation}

All the samples were thawed at room temperature. $5 \mathrm{~g}$ of soil, $5 \mathrm{~g}$ of husked rice, $2 \mathrm{~g}$ of rice hull and $5 \mathrm{~mL}$ of water were weighed into a $50 \mathrm{~mL}$ polypropylene centrifuge tube, respectively. $5 \mathrm{~mL}$ of purified water with $1 \%$ formic acid were added to the rice hull and husked rice sample. $10 \mathrm{~mL}$ of acetonitrile was added in all samples for extraction. All the samples were shaken vigorously for $1 \mathrm{~min}$, then $3 \mathrm{~g}$ of sodium chloride was added, and samples were oscillated for $30 \mathrm{~min}$ in an air bath oscillator at $300 \mathrm{rpm}$. After that, sample tubes were exposed to ultrasonic vibration for $10 \mathrm{~min}$, and then centrifuged at $3500 \mathrm{rpm}$ for $5 \mathrm{~min}$.

For soil and water samples, $1 \mathrm{~mL}$ of the upper layer was placed into a $2 \mathrm{~mL}$ centrifuge tube including $20 \mathrm{mg}$ of PSA and $100 \mathrm{mg}$ of anhydrous magnesium sulfate. The samples were vortexed again for $1 \mathrm{~min}$ and then centrifuged at 10,000 rpm for $5 \mathrm{~min}$. The upper extract was filtered through a $0.22 \mu \mathrm{m}$ filter and transferred into a $2 \mathrm{~mL}$ autosampler vial for HPLC-MS/MS or GC-MS analysis, individually.

For husked rice and rice hull samples, $10 \mathrm{~mL}$ of the upper layer was transferred to a $100 \mathrm{~mL}$ conical flask, evaporated to dryness at $35^{\circ} \mathrm{C}$ on a rotary vacuum evaporator, reconstituted with $1 \mathrm{~mL}$ of acetonitrile and transferred into a $2 \mathrm{~mL}$ single-use centrifuge tube including $50 \mathrm{mg}$ of PSA, $10 \mathrm{mg}$ of $\mathrm{GCB}$, and $150 \mathrm{mg}$ of anhydrous magnesium sulfate. The sample was vortexed vigorously for $1 \mathrm{~min}$ and centrifuged on a microcentrifuge at $10,000 \mathrm{rpm}$ for $5 \mathrm{~min}$. The resulting supernatant was filtered through a $0.22 \mu \mathrm{m}$ filter and transferred into a $2 \mathrm{~mL}$ autosampler vial for HPLC-MS/MS or GC-MS analysis, respectively.

\subsubsection{HPLC-MS/MS Analysis}

The mobile phase was solvent A (methanol) and solvent B ( $0.1 \%$ formic acid in water) $(v / v=90: 10)$ with the flow rate of $0.3 \mathrm{~mL} / \mathrm{min}$. A sample of $5 \mu \mathrm{L}$ was injected and the herbicides were separated on an Agilent ZORBAX SB- $\mathrm{C}_{18}$ reverse-phase column $(50 \mathrm{~mm} \times 2.1 \mathrm{~mm}, 3 \mu \mathrm{m})$. Nitrogen was used as both nebulizer and collision gas in HPLC-MS/MS analysis. The electrospray ionization source (ESI) parameters were as follows: drying gas temperature, $350{ }^{\circ} \mathrm{C}$; gas flow, $8.0 \mathrm{~mL} / \mathrm{min}$; nebulizer gas, $35 \mathrm{psi}$; and capillary voltage, $3000 \mathrm{~V}$. The positive multiple reaction monitoring (MRM) mode was used for monitoring ions transitions. An Agilent Mass Hunter software package was used for method development and data acquisition. Under the above condition, the retention time of pyrazosulfuron-ethyl and bensulfuron-methyl were 7.08 and $6.12 \mathrm{~min}$, individually. The MS parameters and representative chromatograms of pyrazosulfuron-ethyl and bensulfuron-methyl are shown in Table 2 and Figure 2. 
Table 2. Liquid chromatography-tandem mass spectrometry (LC-MS/MS) parameters of pyrazosulfuron-ethyl and bensulfuron-methyl.

\begin{tabular}{|c|c|c|c|c|c|}
\hline Herbicides & $\begin{array}{l}\text { Retention } \\
\text { Time (min) }\end{array}$ & $\begin{array}{l}\text { Qualifying } \\
\text { Ions (m/z) }\end{array}$ & $\begin{array}{l}\text { Quantifying } \\
\text { Ions }(\mathrm{m} / \mathrm{z})\end{array}$ & $\begin{array}{c}\text { Fragmentor } \\
\text { (V) }\end{array}$ & $\begin{array}{l}\text { Collision } \\
\text { Energy (V) }\end{array}$ \\
\hline Pyrazosulfuron-ethyl & 7.08 & $\begin{array}{l}436.9->178.1 \\
436.9->281.9\end{array}$ & $436.9->178.1$ & 135 & $\begin{array}{l}15 \\
20\end{array}$ \\
\hline Bensulfuron-methyl & 6.12 & $\begin{array}{l}411.0->149.0 \\
411.0->182.1\end{array}$ & $411.0->149.0$ & 120 & $\begin{array}{l}20 \\
20\end{array}$ \\
\hline
\end{tabular}
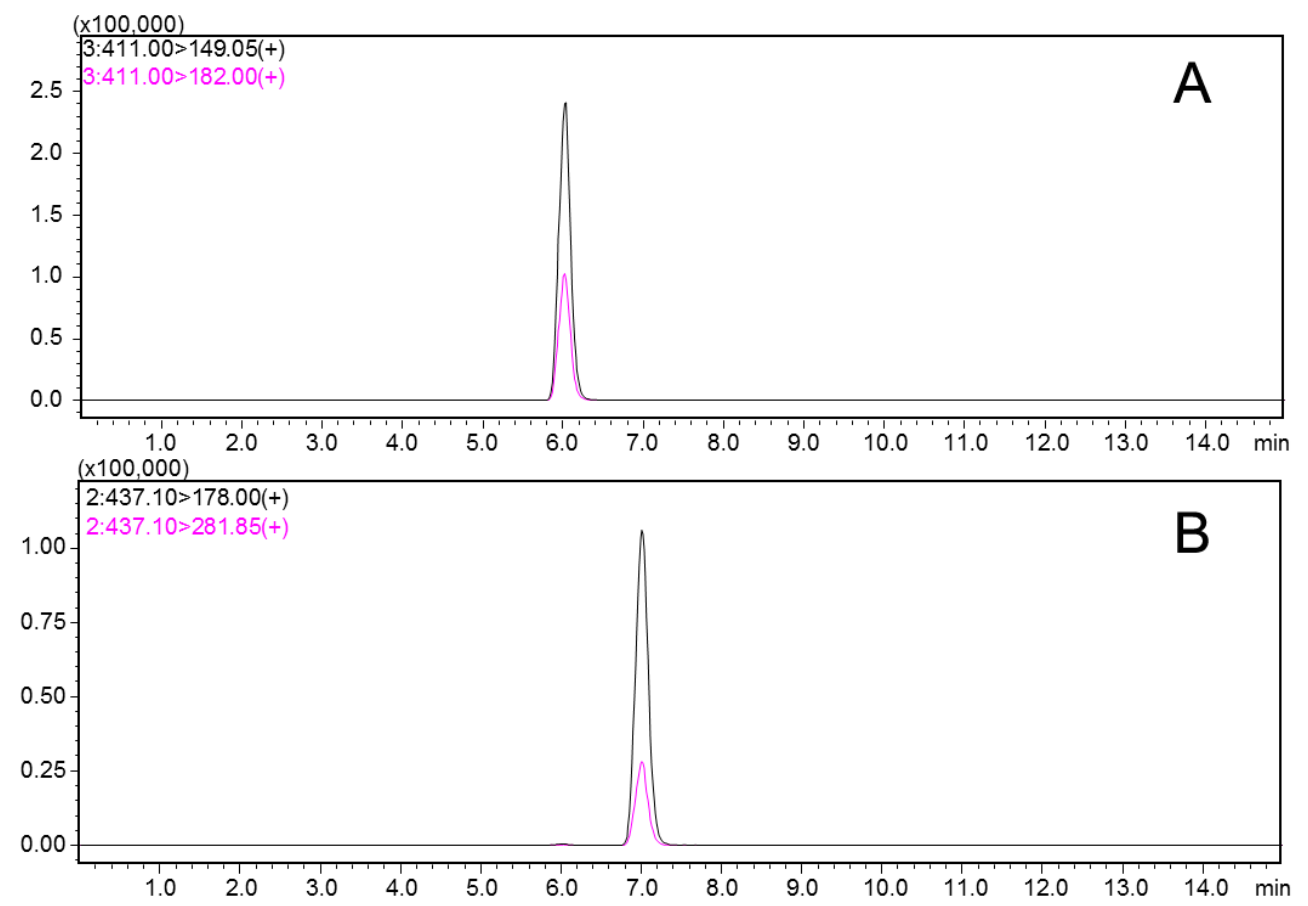

Figure 2. The LC-MS/MS chromatograms of pyrazosulfuron-ethyl (A); bensulfuron-methyl (B) standards in multiple reaction monitoring (MRM) mode.

\subsubsection{GC-MS Analysis}

Acetochlor and butachlor were analyzed on an Agilent 7890-5977B GC-MS system (Agilent, USA). The injector and detector temperature were set at $260^{\circ} \mathrm{C}$ and $280^{\circ} \mathrm{C}$, respectively. Helium was served as the carrier gas at a constant flow rate of $1.0 \mathrm{~mL} / \mathrm{min}$ and a sample of $2 \mu \mathrm{L}$ was injected into the GC-MS system. The separations of two herbicides were performed on a HP- 5 capillary column $(30 \mathrm{~m} \times 0.25 \mathrm{~mm}$ inner diameter and $0.25 \mu \mathrm{m}$ film thickness). Oven temperature program was as follows: the column was held initially at $100^{\circ} \mathrm{C}$ for $1 \mathrm{~min}$, then ramped at $20^{\circ} \mathrm{C} / \mathrm{min}$ to $220^{\circ} \mathrm{C}$, ramped at $1{ }^{\circ} \mathrm{C} / \mathrm{min}$ to $230{ }^{\circ} \mathrm{C}$, further ramped $20^{\circ} \mathrm{C} / \mathrm{min}$ to $260^{\circ} \mathrm{C}$, and held at $260^{\circ} \mathrm{C}$ for $3 \mathrm{~min}$. The MS parameters were as follows: source temperature of $230^{\circ} \mathrm{C}$, emission current of $35 \mu \mathrm{A}$, and energy of $-70 \mathrm{eV}$. The ions transitions were operated in the selective ion monitored (SIM) mode. The retention times of acetochlor and butachlor were 8.58 and $11.22 \mathrm{~min}$, individually. The MS parameters and GC-MS chromatograms of acetochlor and butachlor are listed in Table 3 and Figure 3.

Table 3. Gas chromatography-tandem mass spectrometry (GC-MS) parameters of acetochlor and butachlor.

\begin{tabular}{cccc}
\hline Herbicides & Retention Time (min) & Qualifying Ions (m/z) & Quantifying Ions (m/z) \\
\hline Acetochlor & 8.58 & $146.0,162.0,174.0$ & 146.0 \\
Butachlor & 11.22 & $176.0,160.0,57.0$ & 176.0 \\
\hline
\end{tabular}




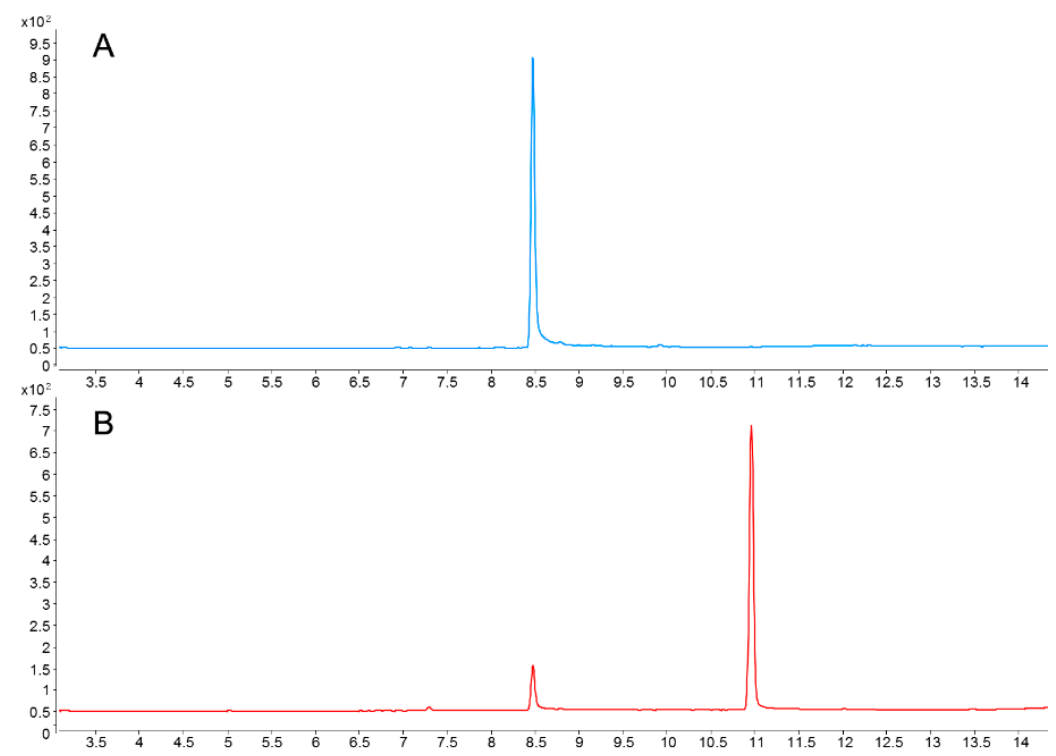

Figure 3. The GC-MS chromatograms of acetochlor $(A, m / z=146)$ and butachlor $(B, m / z=176)$ standards in selected ion monitoring (SIM) mode.

\subsubsection{Data Analysis}

The degradation dynamics of the four herbicides in paddy fields appeared to follow the first-order kinetic reaction and were calculated according to the following equation: $C_{t}=C_{0} e^{-k t}$, where $C_{t}$ and $\mathrm{C}_{0}$ are the concentrations of herbicides at time $\mathrm{t}$ and time 0 after spraying $(\mathrm{mg} / \mathrm{kg})$, respectively, and $\mathrm{k}$ is the degradation rate constant $[37,38]$. The half-life $\left(t_{1 / 2}\right)$ of each herbicide was calculated using the equation: $t_{1 / 2}=\ln 2 / k[39,40]$.

\section{Results}

\subsection{Method Validation}

The performance of the developed method was validated with linearity, accuracy, precision, limit of detection (LOD), and limit of quantitation (LOQ). In order to obtain realistic and accurate results, linearity was evaluated by using the matrix-matched standard calibrations method to eliminate matrix effects. Excellent linearities were acquired with all the determination coefficients $\left(R^{2}\right)$ higher than 0.99 in the range of $0.005-0.5 \mathrm{mg} / \mathrm{L}$ with five calibration points for pyrazosulfuron-ethyl, bensulfuron-methyl and $0.025-1 \mathrm{mg} / \mathrm{L}$ for acetochlor and butachlor, respectively. Quantification was calculated using the calibration curve constructed by linear regressing of herbicide concentrations against peak areas. The accuracy and precision of the method were evaluated by spiking blank samples with corresponding standard solution at three levels $(0.01,0.1$, and $0.5 \mathrm{mg} / \mathrm{L}$ for pyrazosulfuron-ethyl and bensulfuron-methyl in paddy fields; $0.1,0.5$, and $1 \mathrm{mg} / \mathrm{L}$ for acetochlor and butachlor in soil; 0.01 , 0.05 , and $0.5 \mathrm{mg} / \mathrm{L}$ for acetochlor; and $0.05,0.5$, and $1 \mathrm{mg} / \mathrm{L}$ for butachlor in husked rice and rice hull; respectively). The average recoveries of pyrazosulfuron-ethyl, bensulfuron-methyl, acetochlor, and butachlor in paddy environments were $81-106.4 \%, 78.9-102.7 \%, 87.4-99.5 \%$, and $86.3-108 \%$, respectively, with the relative standard deviation (RSD) below $14.9 \%$ (Table 4). The LOD of pyrazosulfuron-ethyl, bensulfuron-methyl, acetochlor, and butachlor in soil, husked rice, and rice hull were $0.04-1 \mathrm{ng}$, at a signal-to-noise $(S / \mathrm{N})$ ratio of 3 . The LOQ was $0.01 \mathrm{mg} / \mathrm{kg}$ for pyrazosulfuron-ethyl and bensulfuron-methyl in all matrices, $0.01 \mathrm{mg} / \mathrm{kg}$ for acetochlor in husked rice and rice hull, $0.05 \mathrm{mg} / \mathrm{kg}$ for butachlor in husked rice and rice hull, and $0.1 \mathrm{mg} / \mathrm{kg}$ for acetochlor and butachlor in soil, respectively, at a signal-to-noise $(S / N)$ ratio of 10 . Such results indicated the established methods were qualified in determining the four herbicides' residue in paddy environments (Table 4). 
Table 4. The average recovery, calibration curve, the limits of detection (LODs), and limits of quantification (LOQs) of the four herbicides in soil, husked rice, and rice hull $(n=5)$.

\begin{tabular}{|c|c|c|c|c|c|c|c|c|}
\hline Herbicides & Sample Matrix & Fortified Level $\left(\mathrm{mg} \cdot \mathrm{kg}^{-1}\right)$ & Average Recovery (\%) & RSD (\%) & Calibration Curve & $\mathbf{R}^{2}$ & LOD (ng) & LOQ $\left(\mathrm{mg} \cdot \mathrm{kg}^{-1}\right)$ \\
\hline \multirow{9}{*}{ Pyrazosulfuron-ethyl } & \multirow{3}{*}{ Soil } & 0.01 & 84.7 & 1.9 & \multirow{3}{*}{$y=1.11 E+06 x-2358.2$} & \multirow{3}{*}{0.9998} & \multirow{3}{*}{0.25} & \multirow{3}{*}{0.01} \\
\hline & & 0.1 & 94.5 & 6.0 & & & & \\
\hline & & 0.5 & 91.8 & 4.2 & & & & \\
\hline & \multirow{3}{*}{ Husked rice } & 0.01 & 92.4 & 3.7 & \multirow{3}{*}{$y=9.31 E+05 x+2447.4$} & \multirow{3}{*}{0.9993} & \multirow{3}{*}{0.25} & \multirow{3}{*}{0.01} \\
\hline & & 0.1 & 102.8 & 1.5 & & & & \\
\hline & & 0.5 & 102.1 & 2.6 & & & & \\
\hline & \multirow{3}{*}{ Rice hull } & 0.01 & 106.4 & 3.7 & \multirow{3}{*}{$y=1.00 E+06 x-3245.4$} & \multirow{3}{*}{0.9998} & \multirow{3}{*}{0.10} & \multirow{3}{*}{0.01} \\
\hline & & 0.1 & 95.3 & 5.1 & & & & \\
\hline & & 0.5 & 81.0 & 3.6 & & & & \\
\hline \multirow{9}{*}{ Bensulfuron-methyl } & \multirow{3}{*}{ Soil } & 0.01 & 95.5 & 10.7 & \multirow{3}{*}{$y=4.63 E+06 x+12105$} & \multirow{3}{*}{0.9999} & \multirow{3}{*}{0.25} & \multirow{3}{*}{0.01} \\
\hline & & 0.05 & 102.7 & 5.1 & & & & \\
\hline & & 0.5 & 78.9 & 3.1 & & & & \\
\hline & \multirow{3}{*}{ Husked rice } & 0.01 & 83.2 & 13.4 & \multirow{3}{*}{$y=4.36 E+06 x+11910.5$} & \multirow{3}{*}{0.9998} & \multirow{3}{*}{0.25} & \\
\hline & & 0.05 & 90.5 & 14.9 & & & & 0.01 \\
\hline & & 0.5 & 80.0 & 9.8 & & & & \\
\hline & & 0.01 & 94.2 & 4.6 & & & & \\
\hline & Rice hull & 0.05 & 92.6 & 9.8 & $y=5.00 E+06 x+9465.6$ & 0.9999 & 0.10 & 0.01 \\
\hline & & 0.5 & 92.4 & 4.9 & & & & \\
\hline & & 0.1 & 96.3 & 2.5 & & & & \\
\hline & Soil & 0.5 & 93.6 & 5.9 & $y=9.31 E+02 x-5.3453$ & 0.9982 & 1.0 & 0.1 \\
\hline & & 1 & 93.8 & 0.9 & & & & \\
\hline & & 0.01 & 94.6 & 3.7 & & & & \\
\hline Acetochlor & Husked rice & 0.05 & 99.5 & 1.2 & $y=9.75 E+02 x-6.546$ & 0.9979 & 0.10 & 0.01 \\
\hline & & 0.5 & 97.6 & 3.8 & & & & \\
\hline & & 0.01 & 87.4 & 9.7 & & & & \\
\hline & Rice hull & 0.05 & 90.8 & 5.8 & $y=9.93 E+02 x-1.5344$ & 0.9994 & 0.04 & 0.01 \\
\hline & & 0.5 & 93.7 & 7.2 & & & & \\
\hline & & 0.1 & 108.0 & 9.2 & & & & \\
\hline & Soil & 0.5 & 90.8 & 6.3 & $y=9.65 E+02 x-1.8882$ & 0.9995 & 1.0 & 0.1 \\
\hline & & 1 & 95.9 & 2.2 & & & & \\
\hline & & 0.05 & 86.3 & 3.6 & & & & \\
\hline Butachlor & Husked rice & 0.5 & 98.4 & 3.8 & $y=9.09 E+02 x+7.9348$ & 0.9988 & 0.50 & 0.05 \\
\hline & & 1 & 98.7 & 3.2 & & & & \\
\hline & & 0.05 & 86.9 & 8.5 & & & & \\
\hline & Rice hull & 0.5 & 97.3 & 9.1 & $\mathrm{y}=9.23 \mathrm{E}+02+3.8587$ & 0.9992 & 0.20 & 0.05 \\
\hline & & 1 & 89.4 & 5.3 & & & & \\
\hline
\end{tabular}




\subsection{Dissipation of Four Herbicides in a Rice Field Ecosystem}

The developed analytical method was applied to dissipation dynamics studies of pyrazosulfuron-ethyl, bensulfuron-methyl, acetochlor, and butachlor after application in an experimental field, respectively. The dissipation curves of four herbicides in soil from different locations are shown in Figures 4 and 5. All the dissipation processes of the four herbicides followed the first-order kinetic reaction, and the dissipation half-life $\left(t_{1 / 2}\right)$, as well as other statistical parameters of the four herbicides, are listed in Tables 5 and 6. The initial residues of pyrazosulfuron-ethyl, bensulfuron-methyl, acetochlor, and butachlor in soil were in the range of $0.4-1.3 \mathrm{mg} / \mathrm{kg}$ at low-dosage application and $0.7-2.1 \mathrm{mg} / \mathrm{kg}$ at high-dosage application. As expected, the gradual and continuous decreases of the four herbicides in paddy soil were observed at different intervals. The four herbicides degraded fast in soil with the average half-life range from 3-14 days after low-dosage application and 4-20 days after high-dosage application. Furthermore, about $90 \%$ of the residues had degraded within 40 days after application. In water samples, the initial residues of pyrazosulfuron-ethyl, bensulfuron-methyl, acetochlor, and butachlor were in the range of $0.18-1.17 \mathrm{mg} / \mathrm{kg}$ after low dosage application and $0.34-2.19 \mathrm{mg} / \mathrm{kg}$ after high dosage application, individually. The four herbicides degraded fast in water with over $95 \%$ of the initial residues dissipated within the first 5 days. Therefore, no dissipation curves and half-lives were obtained in water samples.

Table 5. The dissipation half-lives of four herbicides in rice soil (low-dosage).

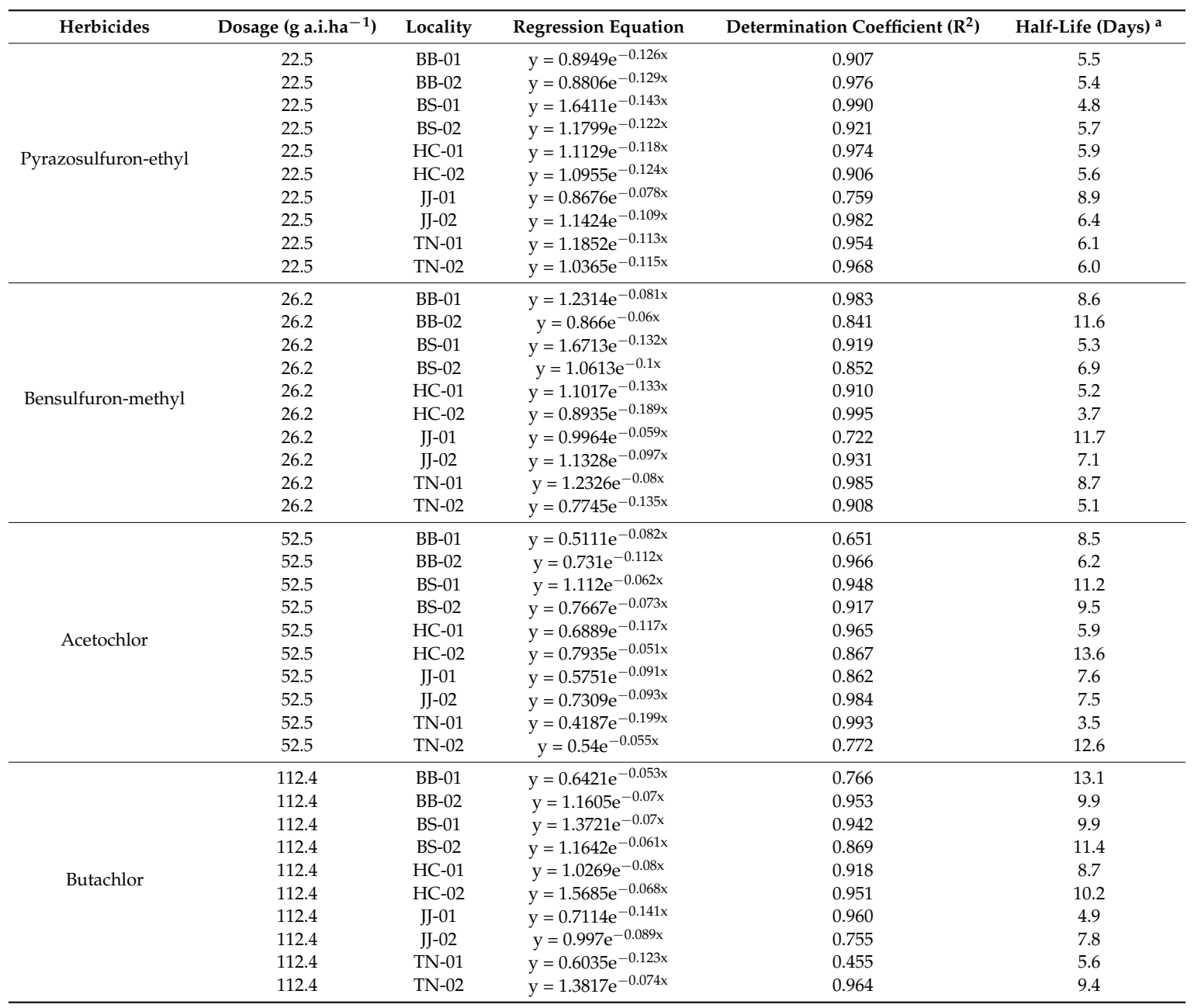

a the half-life calculated using the following equation $t_{1 / 2}=\ln 2 / k$. 
Table 6. The dissipation half-lives of the four herbicides in rice soil (high-dosage).

\begin{tabular}{|c|c|c|c|c|c|}
\hline Herbicides & Dosage (g a.i.ha ${ }^{-1}$ ) & Locality & Regression Equation & $\begin{array}{l}\text { Determination } \\
\text { Coefficient }\left(R^{2}\right)\end{array}$ & Half-Life (Days) $^{\text {a }}$ \\
\hline \multirow{8}{*}{ Pyrazosulfuron-ethyl } & 45 & BB-01 & $y=1.4646 e^{-0.106 x}$ & 0.915 & 6.5 \\
\hline & 45 & BB-02 & $y=1.5816 e^{-0.132 x}$ & 0.932 & 5.3 \\
\hline & 45 & BS-02 & $y=1.515 e^{-0.105 x}$ & 0.938 & 6.6 \\
\hline & 45 & HC-01 & $y=1.4547 e^{-0.089 x}$ & 0.980 & 7.8 \\
\hline & 45 & HC-02 & $y=1.8413 e^{-0.118 x}$ & 0.875 & 5.9 \\
\hline & 45 & $\mathrm{JJ}-02$ & $y=1.5209 e^{-0.082 x}$ & 0.951 & 8.5 \\
\hline & 45 & TN-01 & $y=1.4166 e^{-0.093 x}$ & 0.990 & 7.5 \\
\hline & 45 & $\mathrm{TN}-02$ & $\mathrm{y}=1.4806 \mathrm{e}^{-0.089 \mathrm{x}}$ & 0.977 & 7.8 \\
\hline \multirow{6}{*}{ Bensulfuron-methyl } & 52.4 & BB-01 & $y=2.2066 e^{-0.064 x}$ & 0.774 & 10.8 \\
\hline & 52.4 & BB-02 & $\mathrm{y}=1.217 \mathrm{e}^{-0.091 \mathrm{x}}$ & 0.952 & 7.6 \\
\hline & 52.4 & BS-01 & $y=2.6665 e^{-0.088 x}$ & 0.983 & 7.9 \\
\hline & 52.4 & $\mathrm{JJ}-02$ & $\mathrm{y}=1.635 \mathrm{e}^{-0.079 \mathrm{x}}$ & 0.988 & 8.8 \\
\hline & 52.4 & TN-01 & $y=2.076 e^{-0.096 x}$ & 0.912 & 7.2 \\
\hline & 52.4 & $\mathrm{TN}-02$ & $y=0.7745 e^{-0.075 x}$ & 0.653 & 9.2 \\
\hline \multirow{8}{*}{ Acetochlor } & 105 & BB-01 & $\mathrm{y}=1.1331 \mathrm{e}^{-0.1 \mathrm{x}}$ & 0.843 & 6.9 \\
\hline & 105 & BB-02 & $\mathrm{y}=1.7331 \mathrm{e}^{-0.079 \mathrm{x}}$ & 0.936 & 8.8 \\
\hline & 105 & BS-01 & $y=1.9839 e^{-0.066 x}$ & 0.985 & 10.5 \\
\hline & 105 & BS-02 & $y=1.5256 \mathrm{e}^{-0.076 \mathrm{x}}$ & 0.931 & 9.1 \\
\hline & 105 & HC-01 & $y=1.3609 e^{-0.073 x}$ & 0.918 & 9.5 \\
\hline & 105 & HC-02 & $y=1.2829 e^{-0.055 x}$ & 0.866 & 12.6 \\
\hline & 105 & $\mathrm{JJ}-01$ & $y=1.2586 e^{-0.107 x}$ & 0.954 & 6.5 \\
\hline & 105 & $\mathrm{JJ}-02$ & $y=1.765 e^{-0.121 x}$ & 0.962 & 5.7 \\
\hline \multirow{5}{*}{ Butachlor } & 224.8 & HC-02 & $y=2.3666 e^{-0.064 x}$ & 0.951 & 10.8 \\
\hline & 224.8 & $\mathrm{JJ}-01$ & $y=1.7142 e^{-0.077 x}$ & 0.900 & 9.0 \\
\hline & 224.8 & $\mathrm{JJ}-02$ & $y=1.5782 e^{-0.079 x}$ & 0.938 & 8.8 \\
\hline & 224.8 & TN-01 & $y=1.7773 e^{-0.044 x}$ & 0.837 & 15.8 \\
\hline & 224.8 & $\mathrm{TN}-02$ & $y=1.8878 e^{-0.063 x}$ & 0.949 & 11.0 \\
\hline
\end{tabular}

${ }^{a}$ the half-life calculated using the following equation $t_{1 / 2}=\ln 2 / k$. 

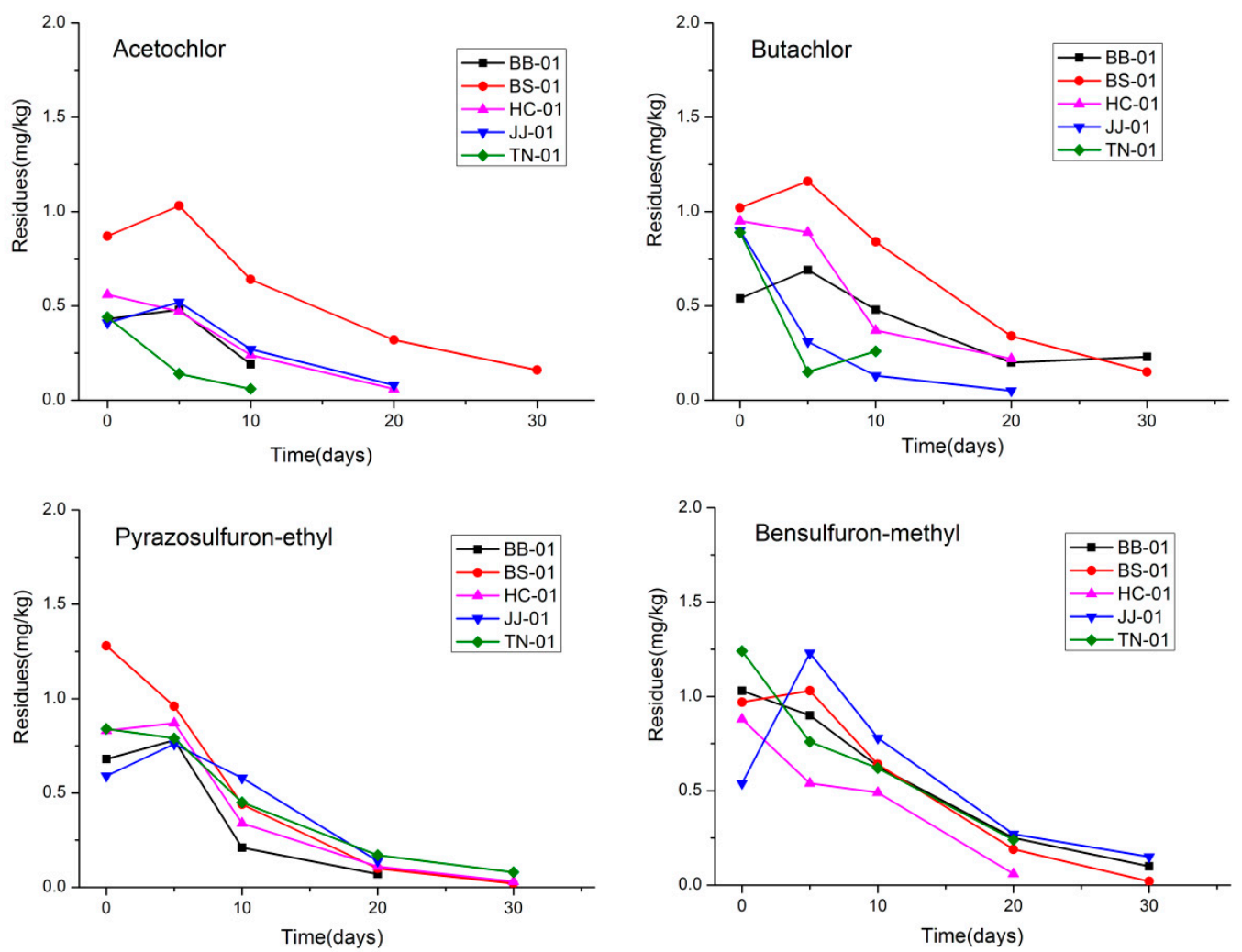

Figure 4. Representative dissipation curves of the four herbicides in soil samples in five different geographic zones after low-dosage application

$\boldsymbol{\square}, \mathrm{BB}-01, \bullet, \mathrm{BS}-01, \boldsymbol{\Lambda}, \mathrm{HC}-01, \mathbf{\nabla}, \mathrm{JJ}-01, \bullet, \mathrm{TN}-01)$.
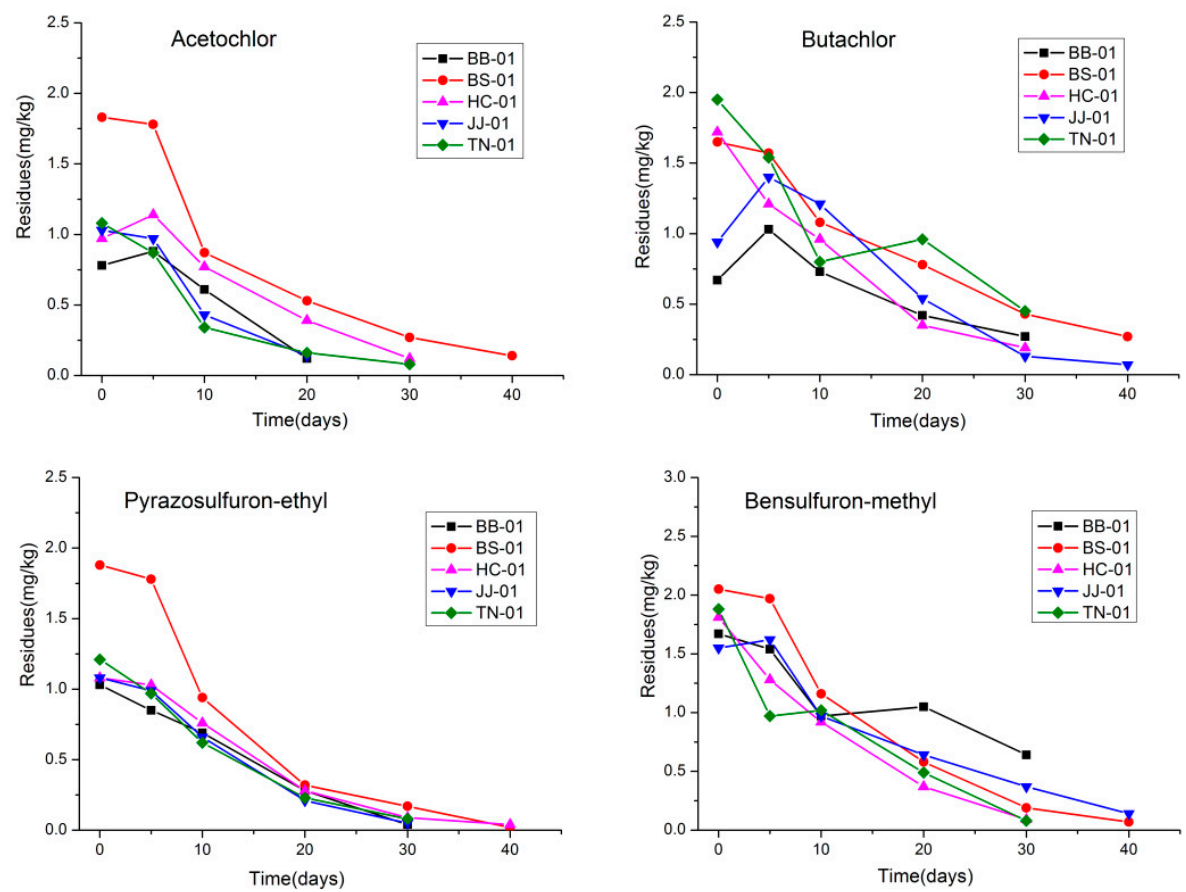

Figure 5. Representative dissipation curves of the four herbicides in soil samples in five different geographic zones after high-dosage application ( $\mathbf{\square}, \mathrm{BB}-01, \bullet$, BS-01, $\mathbf{\Delta}, \mathrm{HC}-01, \mathbf{\nabla}, \mathrm{JJ}-01, \bullet, \mathrm{TN}-01)$.

\subsection{Final Residue of Four Herbicides}

The final residues of pyrazosulfuron-ethyl, bensulfuron-methyl, acetochlor, and butachlor in husked rice and rice hull samples collected from treated plots at harvest time are shown in Tables S1 
and S2. Final residue levels of four herbicides in all samples with different dosage revealed no regional difference was observed at ten experimental sites. The results indicated that the four herbicides' residues were not detectable or below their respective LOQs in husked rice and rice hull, which indicated pyrazosulfuron-ethyl, bensulfuron-methyl, acetochlor, and butachlor were safe on rice under the recommended dosage and two times the recommended dosage at GAP condition.

\section{Discussion}

\subsection{Optimization of HPLC-MS/MS Method}

The compositions of the mobile phase play a vital role in selectivity, peak shape, and proper retention time in HPLC separations, and formic acid contributed to the protonation of analytes in LC-MS/MS analysis [41]. In this study, $90 \%$ methanol and $10 \%$ water containing $0.1 \%$ formic acid were used as mobile phase for pyrazosulfuron-ethyl and bensulfuron-methyl separation, and there were no interfering peaks near pyrazosulfuron-ethyl and bensulfuron-methyl peaks. Each HPLC-MS/MS run time was less than $10 \mathrm{~min}$. Moreover, the precursor ion and the two most abundant product ions were chosen to construct MRM transitions for pyrazosulfuron-ethyl and bensulfuron-methyl HPLC-MS/MS analysis. In order to obtain powerful sensitivity, the fragmentor voltage and collision energy were optimized for the precursor ion and every specific transition. The suitable HPLC-MS/MS conditions for pyrazosulfuron-ethyl and bensulfuron-methyl are shown in Table 1. In our study, the QuEChERS sample preparation coupled with the HPLC-MS/MS method has a lower LOD, reasonable recovery and relative standard deviation (RSD) than solid phase extraction coupled with liquid chromatography-diode array detector(SPE-LC-DAD) [42] and solid phase extraction coupled with liquid chromatography-tandem mass spectrometry (SPE-LC-MS) [43], respectively (Table S3).

\subsection{Optimization of GC-MS Method}

In this study, acetochlor and butachlor were determined on GC-MS according to their specific product ions and retention time using selected ion monitoring (SIM) mode. The three most abundant ions for acetochlor and butachlor were 146,162, 174 and 176, 160, and 57, respectively. Thus, 146 and 176 were chosen as quantitation ions for acetochlor and butachlor analysis considering their selectivity and sensitivity in the GC-MS system, and the qualitative ions were 162, 174 and 160, $57 \mathrm{~m} / \mathrm{z}$ for acetochlor and butachlor, individually. Under the above condition, the retention times of acetochlor and butachlor were 8.58 and $11.22 \mathrm{~min}$, respectively (Table 2). The developed method performed satisfactory results with high sensitivity and specificity in validated experiments and real sample determination. Compared with previous studies, the QuEChERS sample preparation coupled with the GC-MS method developed in our study has a lower LOD, reasonable recovery and relative standard deviation (RSD) than liquid-liquid extraction coupled with gas chromatography-tandem mass spectrometry(LLE-GC-MS) [44], solid phase micro-extraction coupled with gas chromatography-tandem mass spectrometry (SPME-GC-MS) [45], and dispersive liquid phase micro-extraction coupled with gas chromatography-tandem mass spectrometry (DLPME-GC-MS) [33], respectively (Table S4).

\subsection{Four Herbicides' Dissipation and Final Residue}

In the context of this study, the results indicated that $50 \%$ of the initial residues of four herbicides were dissipated in soil within 12 days after treatment. And about $90 \%$ of the residues were degraded within 40 days. Furthermore, the dissipations of four herbicides in water were much faster than that in soil, and the herbicides were not detectable after 5 days in water after treatment. Besides the physical and chemical properties of pesticides, other factors such as $\mathrm{pH}$, light, heat, and dissolved oxygen concentration could affect the herbicides' dissipation in water [10,46]. In soil, studies showed that sulfonylurea herbicides' dissipation was highly related to $\mathrm{pH}$ and acidic soil could accelerate degradation $[12,47,48]$. Ye et al. reported that soil properties and temperature influenced the dissipation rate of acetochlor in soil $[49,50]$. Oliveira et al. found that the half-lives of acetochlor in surface soil 
were 6.51-13.9 days, which was consistent with our study [51]. Rao et al. reported that butachlor dissipation might be due to physical parameters like temperature, wind velocity, and moisture level and the half-lives were 12.5-21.5 days, which is also consistent with our research [14]. The different dissipation trends of the four herbicides in water and soil from different places in our study may also have been affected factors including $\mathrm{pH}$, dissolved oxygen concentration, moisture, soil property, and microorganisms [52,53].

In the final residue trials, no herbicide residue was found in husked rice and rice hull, even though double the recommended dosage of the four herbicides was used on transplanted rice fields. The results indicate the use and consumption of the four herbicides following double the manufacturers' recommended dosage on rice are safe under an open field environment. Nevertheless, it should be emphasized that the use of herbicides in paddy fields should strictly follow the instructions provided by the manufacture and comply with government regulations.

\subsection{Dietary Risk Assessment}

The acceptable daily intake (ADI) for pyrazosulfuron-ethyl, bensulfuron-methyl, acetochlor, and butachlor are $0.043,0.2,0.02$ and $0.1 \mathrm{mg} / \mathrm{kg}(\mathrm{bw})$, respectively, according to maximum residue limits for pesticides in food in china (GB2763-2016) [54]. In this study, the final residues of four herbicides in the rice samples were all below the LOQs at harvest time. Therefore, the supervised trial median residue (STMR) value may be assumed to be at the LOQ. The LOQ of pyrazosulfuron-ethyl, bensulfuron-methyl, and acetochlor was $0.01 \mathrm{mg} / \mathrm{kg}$, and butachlor was $0.05 \mathrm{mg} / \mathrm{kg}$, respectively. The national estimated daily intake (NEDI) of the four herbicides was defined by the following equation: $\mathrm{NEDI}=\mathrm{STMR} \times \mathrm{Fi} / b_{w}$, where the average body weight $\left(b_{w}\right)$ of an adult in China was estimated at $60 \mathrm{~kg}$, and the intake of an adult per day ( $\mathrm{Fi})$ was $0.3 \mathrm{~kg}$ per Chinese person when consuming rice, which was provided based on the dietary guidelines issued by the Health Ministry of China [55]. According to the equation, the NEDI for pyrazosulfuron-ethyl, bensulfuron-methyl, acetochlor, and butachlor was $5 \times 10^{-5} \mathrm{mg} / \mathrm{kg}, 5 \times 10^{-5} \mathrm{mg} / \mathrm{kg}, 5 \times 10^{-5} \mathrm{mg} / \mathrm{kg}$, and $2.5 \times 10^{-4} \mathrm{mg} / \mathrm{kg}$, respectively. Consequently, the NEDI of the four herbicides is fairly low; the daily dietary intake of pyrazosulfuron-ethyl, bensulfuron-methyl, acetochlor, and butachlor is $0.12 \%, 0.03 \%, 0.25 \%$, and $0.25 \%$ of the ADI in China, respectively. Such results imply that the potential health risks induced by the four herbicides are not significant in paddy fields, even at double the recommended dosage.

\section{Conclusions}

In the context of this study, a quick, easy, cheap, rugged, safe (QuEChERS) extraction method, coupled with HPLC-MS/MS and GC-MS, was developed to determine the dissipation dynamics and residue of pyrazosulfuron-ethyl, bensulfuron-methyl, acetochlor, and butachlor in rice cropping systems. The average recoveries of the four herbicides ranged from $78.9-108 \%$ with relative standard deviations (RSDs) less than 15\% at three different fortified levels for soil, rice hull, and husked rice. The dissipation results indicate that the average half-lives of the four herbicides in soil are in the range of 3.5-17.8 days, and more than $95 \%$ of all herbicides dissipated within 5 days in water. Furthermore, the final residues of four herbicides were all below LOQ at harvest time. Such results highlight the dissipation dynamics and residue of four herbicides in rice cropping systems and contribute to risk assessment as well as scientific guidance on the proper and safe application of rice herbicides in paddy fields.

Supplementary Materials: The following are available online at http:/ / www.mdpi.com/1660-4601/16/2/236/s1, Table S1: Final residues of four herbicides in husked rice sample. Table S2: Final residues of four herbicides in rice hull sample. Table S3: Comparison of QuEChERS-HPLC-MS with other analytical methods for determination of sulfonylurea herbicides. Table S4: Comparison of QuEChERS-GC-MS with other analytical methods for determination of amide herbicides.

Author Contributions: P.Z., L.H., and H.Z. conceived and designed this study; P.Z., Q.Y., Y.H., X.H., and Y.H. conducted the experiments; Q.Y., Y.H., and P.Z. analyzed the data; P.Z. and L.H. contributed reagents, material, analysis tools and prepared the manuscript. All authors read and approved the final manuscript. 
Funding: This research was funded by National Natural Science Foundation of China (31801745), China Postdoctoral Science Foundation (2017M612889), Chongqing Postdoctoral Science Foundation (Xm2017073), Fundamental Research Funds for the Central Universities (XDJK2017C067, XDJK2017C066) and National Special Research Fund for Non-Profit Sector (Agriculture) (201503107).

Conflicts of Interest: the authors declare no conflicts of interest.

\section{References}

1. Rao, G.S.; Deveshwar, P.; Sharma, M.; Kapoor, S.; Rao, K.V. Evolvement of transgenic male-sterility and fertility-restoration system in rice for production of hybrid varieties. Plant Mol. Biol. 2018, 96, 35-51. [CrossRef] [PubMed]

2. Zhang, Y.; Zhang, L.; Xu, P.; Li, J.; Wang, H. Dissipation and residue of pymetrozine in rice field ecosystem. Environ. Monit. Assess. 2015, 187, 78-85. [CrossRef] [PubMed]

3. Zhang, X.; Shen, Y.; Yu, X.Y.; Liu, X.J. Dissipation of chlorpyrifos and residue analysis in rice, soil and water under paddy field conditions. Ecotoxicol. Environ. Saf. 2012, 78, 276-280. [CrossRef] [PubMed]

4. Zhang, F.; Wang, L.; Zhou, L.; Pan, C. Dissipation and residues of monosultap in rice plant and environment. Bull. Environ. Contam. Toxicol. 2012, 88, 362-367. [CrossRef] [PubMed]

5. Zhang, Q.; Zhao, Y.; Fan, S.; Bai, A.; Li, X.; Pan, C. Dissipation and residues of bispyribac-sodium in rice and environment. Environ. Monit. Assess. 2013, 185, 9743-9749. [CrossRef] [PubMed]

6. Hosoya, K.; Sugiyama, S. Weed communities and their negative impact on rice yield in no-input paddy fields in the northern part of Japan. Biol. Agric. Hortic. 2017, 33, 215-224. [CrossRef]

7. Li, H.; Feng, Y.; Li, X.; Zeng, D. Analytical Confirmation of Various Herbicides in Drinking Water Resources in Sugarcane Production Regions of Guangxi, China. Bull. Environ. Contam. Toxicol. 2018, 100, 815-820. [CrossRef]

8. Li, C.; Lu, A.; Wang, J.; Li, J.; Ping, H.; Luan, Y.; Chen, J.; Ha, X. Determination of five sulfonylurea herbicides in environmental waters and soil by ultra high performance liquid chromatography with tandem mass spectrometry after extraction using graphene. J. Sep. Sci. 2014, 37, 3714-3721. [CrossRef]

9. Yokley, R.A.; Mayer, L.C.; Huang, S.B.; Vargo, J.D. Analytical method for the determination of metolachlor, acetochlor, alachlor, dimethenamid, and their corresponding ethanesulfonic and oxanillic acid degradates in water using SPE and LC/ESI-MS/MS. Anal. Chem. 2002, 74, 3754-3759. [CrossRef]

10. Singh, S.B.; Sharma, R.; Singh, N. Persistence of pyrazosulfuron in rice-field and laboratory soil under Indian tropical conditions. Pest Manag. Sci. 2012, 68, 828-833. [CrossRef]

11. Ok, J.; Doan, N.H.; Watanabe, H.; Thuyet, D.Q.; Boulange, J. Behavior of butachlor and pyrazosulfuron-ethyl in paddy water using micro paddy lysimeters under different temperature conditions in spring and summer. Bull. Environ. Contam. Toxicol. 2012, 89, 306-311. [CrossRef]

12. Singh, N.; Singh, S.B. Translocation and degradation of pyrazosulfuron-ethyl in rice soil. Pest Manag. Sci. 2011, 67, 1451-1456. [CrossRef] [PubMed]

13. Cara, I.G.; Lipsa, F.D.; Cara, M.S.; Burtan, L.; Topa, D.; Jitareanu, G. Dissipation of Acetochlor and Residue Analysis in Maize and Soil under Field Conditions. Agrolife Sci. J. 2017, 6, 48-55.

14. Rao, P.C.; Lakshmi, C.S.R.; Madhavi, M.; Swapna, G.; Sireesha, A. Butachlor dissipation in rice grown soil and its residues in grain. Indian J. Weed Sci. 2012, 44, 84-87.

15. Chopra, N.K. Effect of doses and stages of application of pyrazosulfuron ethyl on weeds in transplanted rice. Indian J. Weed Sci. 2003, 35, 27-29.

16. Akira, O.; Jong, Y.P.; Kozo, I.; Hiroshi, M. Selective mode of action of bensulfuron methyl among rice cultivates. J. Weed Sci. Technol. 1991, 36, 27-35.

17. Rajkhowa, D.J.; Gogol, A.K.; Kandali, R.; Borua, I.C. Effect of dose and stage of application of acetochlor in transplanted rice. Indian J. Weed Sci. 2004, 36, 60-63.

18. Narwal, S.; Singh, S.; Malik, R.K.; Panwar, K.S. Effect of acetochlorand ready mix of anilofos ethoxysulfuron on divergent weed flora in transplanted rice. Indian J. Weed Sci. 2002, 34, $28-31$.

19. Tomlin, C. The Pesticide Manual, 15th ed.; British Crop Production Council: Hampshire, UK, 2009.

20. Janaki, P.; Nithya, C.; Kalaiyarasi, D.; Sakthivel, N.; Nk, P.; Chinnusamy, C. Residue of bensulfuron methyl in soil and rice following its pre- and post-emergence application. Plant Soil Environ. 2016, 62, 428-434. [CrossRef] 
21. Kaur, P.; Randhawa, S.K.; Duhan, A.; Bhullar, M.S. Influence of Long Term Application of Butachlor on its Dissipation and Harvest Residues in Soil and Rice. Bull. Environ. Contam. Toxicol. 2017, 98, 874-880. [CrossRef]

22. Park, T.S.; Moon, B.C.; Cho, J.R. An Overview of Resistant Weeds to Sulfonylurea Herbicides in Rice Field, Korea. Korean J. Weed Sci. 2005, 25, 67-74.

23. Lee, I.Y.; Won, T.J.; Seo, Y.H.; Kim, E.J.; Yun, Y.T.; Cho, S.H.; Kwon, O.D.; Kim, S.K.; Chung, W.G.; Park, T.S.; et al. Occurrence Trends of SU-Herbicide Resistant Weeds in Paddy Fields in Korea. Weed Turfgrass Sci. 2013, 2, 318-321. [CrossRef]

24. Yamada, Y.; Tominaga, T.; Ohsako, T. Microsatellite variability of sulfonylurea-resistant and susceptible populations of Schoenoplectus juncoides (Cyperaceae) in Kinki, Japan. Weed Res. 2013, 53, 429-439. [CrossRef]

25. Su, S.Q. Herbicide-Resistant Weeds in Paddy Field and their Control. Pesticides 2001, 7, 43-48.

26. Rebelo, A.M.; Dolzan, M.D.; Heller, M.; Deschamps, F.C.; Abate, G.; Micke, G.A.; Grassi, M.T. Simultaneous Determination of Herbicides in Rice by QuEChERS and LC-MS/MS Using Matrix-Matched Calibration. J. Braz. Chem. Soc. 2015, 27, 186-193. [CrossRef]

27. Liang, P.; Wang, J.J.; Liu, G.J.; Guan, J.Y. Determination of sulfonylurea herbicides in food crops by matrix solid-phase dispersion extraction coupled with high-performance liquid chromatography. Food Anal. Method 2014, 7, 1530-1535. [CrossRef]

28. Berger, B.M.; Wolfe, N.L. Multiresidue determination of sulfonylurea herbicides by capillary electrophoresis for hydrolysis studies in water and sediments. Anal. Bioanal. Chem. 1996, 356, 508-511. [CrossRef]

29. Zhang, Y.; Wang, J.; Wang, G.; Gao, C.; Yan, Y.; Wen, B. Optimization of derivatization procedure and gas chromatography-mass spectrometry method for determination of bensulfuron-methyl herbicide residues in water. J. Chromatogr. B Anal. Technol. Biomed. Life Sci. 2015, 995-996, 31-37. [CrossRef]

30. Miyake, S.; Ishii, Y.; Yamaguchi, Y.; Ohde, K.; Motoki, M.; Kawata, M.; Ito, S.; Yuasa, Y.; Ohkawa, H. Simple Determination of Herbicides in Rice Paddy Water by Immunoassay. ACS Symp. Ser. 2003, 853, 124-138.

31. Fenoll, J.; Hellin, P.; Sabater, P.; Flores, P.; Navarro, S. Trace analysis of sulfonylurea herbicides in water samples by solid-phase extraction and liquid chromatography-tandem mass spectrometry. Talanta 2012, 101, 273-282. [CrossRef]

32. Zhang, Y.; Yang, J.; Shi, R.; Su, Q.; Yao, L.; Li, P. Determination of acetanilide herbicides in cereal crops using accelerated solvent extraction, solid-phase extraction and gas chromatography-electron capture detector. J. Sep. Sci. 2011, 34, 1675-1682. [CrossRef] [PubMed]

33. Zhao, R.S.; Diao, C.P.; Wang, X.; Jiang, T.; Yuan, J.P. Rapid determination of amide herbicides in environmental water samples with dispersive liquid-liquid microextraction prior to gas chromatography-mass spectrometry. Anal. Bioanal. Chem. 2008, 391, 2915-2921. [CrossRef] [PubMed]

34. Rejczak, T.; Tuzimski, T. Recent Trends in Sample Preparation and Liquid Chromatography/Mass Spectrometry for Pesticide Residue Analysis in Food and Related Matrixes. J. AOAC Int. 2015, 98, 1143-1162. [CrossRef] [PubMed]

35. Hu, M.F.; Chen, W.Y.; Liu, Y.; Zhang, D.Y.; Chen, A.; Liu, J.Y.; Luo, X.W.; Yan, Q.P. Determination of herbicide pyraclonil residue in rice, soil and water using high-performance liquid chromatography/tandem mass spectrometry. Anal. Methods 2017, 9, 4790-4796. [CrossRef]

36. Institute for the Control of Agrochemicals, Ministry of Agriculture. Guidelines on Pesticide Residue Trials (NY/T 788-2004); Institute for the Control of Agrochemicals, Ministry of Agriculture: Beijing, China, 2004.

37. Diao, J.; Lv, C.; Wang, X.; Dang, Z.; Zhu, W.; Zhou, Z. Influence of soil properties on the enantioselective dissipation of the herbicide lactofen in soils. J. Agric. Food Chem. 2009, 57, 5865-5871. [CrossRef] [PubMed]

38. Diao, J.; Xu, P.; Wang, P.; Lu, Y.; Lu, D.; Zhou, Z. Environmental behavior of the chiral aryloxyphenoxypropionate herbicide diclofop-methyl and diclofop: Enantiomerization and enantioselective degradation in soil. Environ. Sci. Technol. 2010, 44, 2042-2047. [CrossRef]

39. Diao, J.; Xu, P.; Wang, P.; Lu, D.; Lu, Y.; Zhou, Z. Enantioselective Degradation in Sediment and Aquatic Toxicity to Daphnia magna of the Herbicide Lactofen Enantiomers. J. Agric. Food Chem. 2010, 58, 2439-2445. [CrossRef]

40. Liu, T.; Wang, P.; Lu, Y.; Zhou, G.; Diao, J.; Zhou, Z. Enantioselective bioaccumulation of soil-associated fipronil enantiomers in Tubifex tubifex. J. Hazard. Mater. 2012, 219-220, 50-56. [CrossRef] 
41. You, X.; Liang, L.; Liu, F. Dissipation and residues of clethodim and its oxidation metabolites in a rape-field ecosystem using QuEChERS and liquid chromatography/tandem mass spectrometry. Food Chem. 2014, 143, 170-174. [CrossRef]

42. Roehrs, R.; Zanella, R.; Pizzuti, I.; Adaime, M.B.; Pareja, L.; Niell, S.; Cesio, M.V.; Heinzen, H. Liquid chromatographic-diode-array detection multiresidue determination of rice herbicides in drinking and paddy-field water. J. AOAC Int. 2009, 92, 1190-1195.

43. Ayano, E.; Kanazawa, H.; Ando, M.; Nishimura, T. Determination and quantitation of sulfonylurea and urea herbicides in water samples using liquid chromatography with electrospray ionization mass spectrometric detection. Anal. Chim. Acta 2004, 507, 211-218. [CrossRef]

44. Wang, L.B.; Li, C.; Peng, C.F.; Li, X.Q.; Xu, C.L. A Rapid Multi-Residue Determination Method of Herbicides in Grain by GC-MS-SIM. J. Chromatogr. Sci. 2008, 46, 424-429. [CrossRef] [PubMed]

45. Xu, X.; Yang, H.; Wang, L.; Han, B.; Wang, X.; Lee, S.C. Analysis of chloroacetanilide herbicides in water samples by solid-phase microextraction coupled with gas chromatography-mass spectrometry. Anal. Chim. Acta 2007, 591, 87-96. [CrossRef]

46. Malhat, F.; Badawy, H.M.; Barakat, D.A.; Saber, A.N. Residues, dissipation and safety evaluation of chromafenozide in strawberry under open field conditions. Food Chem. 2014, 152, 18-22. [CrossRef] [PubMed]

47. Zhou, S.; Hua, X.W.; Wei, W.; Gu, Y.C.; Liu, X.; Chen, J.; Chen, M.; Xie, Y.T.; Zhou, S.; Meng, X.D. Research on Controllable Degradation of Novel Sulfonylurea Herbicides in Acidic and Alkaline Soils. J. Agric. Food Chem. 2017, 65, 7661-7668. [CrossRef] [PubMed]

48. Singh, S.B.; Neera, S. Degradation behaviour of pyrazosulfuron-ethyl in water as affected by pH. J. Environ. Sci. Health Part B Pestic. Food Contam. Agric. Wastes 2013, 48, 266-271. [CrossRef] [PubMed]

49. Ye, C. Environmental Behavior of the Herbicide Acetochlor in Soil. Bull. Environ. Contam. Toxicol. 2003, 71, 919-923. [CrossRef]

50. Hu, J.Y.; Zhen, Z.H.; Deng, Z.B. Simultaneous determination of acetochlor and propisochlor residues in corn and soil by solid phase extraction and gas chromatography with electron capture detection. Bull. Environ. Contam. Toxicol. 2011, 86, 95-100. [CrossRef]

51. Oliveira, R.S.; Koskinen, W.C.; Graff, C.D.; Anderson, J.L.; Mulla, D.J.; Nater, E.A.; Alonso, D.G. Acetochlor Persistence in Surface and Subsurface Soil Samples. Water Air Soil Pollut. 2013, 224, 1747-1751. [CrossRef]

52. Malhat, F.; Kamel, E.; Saber, A.; Hassan, E.; Youssef, A.; Almaz, M.; Hassan, A.; Fayz Ael, S. Residues and dissipation of kresoxim methyl in apple under field condition. Food Chem. 2013, 140, 371-374. [CrossRef]

53. Kumar, V.; Sood, C.; Jaggi, S.; Ravindranath, S.D.; Bhardwaj, S.P.; Shanker, A. Dissipation behavior of propargite-An acaricide residues in soil, apple (Malus pumila) and tea (Camellia sinensis). Chemosphere 2005, 58, 837-843. [CrossRef] [PubMed]

54. National Food Safety Standard-Maximum Residue Limits for Pesticides in Food(GB2763-2016); Ministry of Agriculture and Rural Affairs: Beijing, China, 2016; pp. 1-253.

55. Ge, K.Y.; Jia, J.B.; Liu, H. Food-based dietary guidelines in China practices and problems. Ann. Nutr. Metab. 2007, 51, 26-31. [CrossRef]

(C) 2019 by the authors. Licensee MDPI, Basel, Switzerland. This article is an open access article distributed under the terms and conditions of the Creative Commons Attribution (CC BY) license (http://creativecommons.org/licenses/by/4.0/). 